\title{
The Clinical Ethics Consultant: What Role is There for Religious Beliefs?
}

\author{
J. Clint Parker
}

Published online: 27 May 2019

(c) Springer Nature B.V. 2019

\begin{abstract}
Religions often operate as comprehensive worldviews, attempting to answer the deepest existential questions that human beings can ask: Who am I? Where do I come from? Where am I going after I die? How should I live? Often ethical systems are embedded and justified within these broader narratives. Inevitably, the clinical ethics consultant will encounter and engage with religiously based ethical systems. In this issue, the authors reflect seriously and deeply on the implications of such engagement.
\end{abstract}

Keywords Clinical ethics consultation $\cdot$ Religion $\cdot$ Clinical ethics

\section{Introduction}

Patients, their surrogates, and clinicians often justify their moral beliefs about what may, ought, and ought not be done in particular cases by making reference to their religion or religious sources of moral authority. For many religious believers, morality is one part of a broader religious worldview that seeks to answer not only questions about what is good and right, but also questions about why we exist, what happens to us when we die, whether there is a God (or gods) and if there is, what God is like. The meta-ethical justification for their moral beliefs is intimately bound up with their religious worldview and its sources of moral authority. It is also not uncommon for clinical ethics consultants (CECs) to be brought into ethical disagreements when one side in the disagreement articulates their moral views with explicitly religiously based justifications. Further, CECs may also have explicitly religiously based justifications for their own ethical views. In this special thematic issue, the authors seek to explore through case analysis and argumentation the interplay and intersection of religion and clinical ethics consultation.

\section{J. Clint Parker}

parkerjo@ecu.edu

1 Department of Bioethics and Interdisciplinary Studies, Brody School of Medicine, East Carolina University, 600 Moye Blvd., Brody 2S-17, Mailstop 641, Greenville, NC 27834, USA 


\section{Religion and Clinical Ethics Consultation}

In her article, "The Appropriate Role of a Clinical Ethics Consultant's Religious Worldview in Consultative Work: Nearly None", Janet Malek defends the strong claim that "a clinical ethics consultant's religious worldview has no place in developing ethical recommendations or communicating about them with patients, surrogates, and clinicians" (Malek 2019, p. 92). She notes that religious views might affect a CEC's actual ethical analysis, might shape their conversations with patients when attempting to elucidate a patient's values, and might be a point of commonality with patients or surrogates that a CEC uses to develop rapport. She argues that each of these ways religion might enter into the CEC's work has problems. The first two ways are illicit and should be avoided all together, and the third way should be pursued only with caution.

Malek argues that in areas in which there is no bioethical consensus, the CEC should use a methodology for ethical analysis that utilizes "accepted moral principles" (Malek 2019, p. 95). She argues that appeals to tenets in a CEC's religious worldview, "whether implicit or explicit, have no place in this consultation methodology" (Malek 2019, p. 95). She worries that an ethical recommendation based on appeals to tenets in a CEC's religious worldview would "represent an imposition of the consultant's religiously-based beliefs and values" on the patient (Malek 2019, p. 95). She also argues that CECs should strive for consistency with one another in ethical analysis and minimize variation in the substance of ethical recommendations. Given this goal, she argues, "there is little room to accommodate variation in consultation practices based on an individual consultant's religious worldview" (Malek 2019, p. 96).

Malek also worries that when CECs utilize their own religious worldviews to help patients draw out the implications of and values within their religiously based ethical systems that they are utilizing "a set of considerations that are beyond the scope of bioethical methodology" and that such activities should be delegated to "a chaplain or other individual whose role it is to address such questions" (Malek 2019, p. 95). Finally, while Malek does cautiously open the door to CECs utilizing religion to build rapport with patients or surrogates, this should be done by CECs only if "others initiate their inclusion and if they can do so with sincerity” (Malek 2019, p. 99).

In stark contrast, in his article "Religion, Authenticity, and Clinical Ethics Consultation" Clint Parker argues that there is no professional obligation for CECs "to refrain from utilizing distinctively religious background beliefs when making ethical judgments in their consultative capacity" (Parker 2019, p. 103). In his paper, Parker begins by presenting a case in which three different CECs provide differing moral advice for differing moral reasons. Parker then argues that each of the CECs has met their professional obligations. He lays out six possible activities in which a CEC might engage and the goals associated with these activities. He argues that in regards to making independent ethical judgments in cases, the goal of the CEC, as for any moral agent, is justified, true belief. As long as the 
CEC has diligently attempted to come to justified, true beliefs regarding a case, the CEC has fulfilled his professional obligation.

The process of coming to justified, true ethical beliefs; however, inevitably involves testing these beliefs for coherence against one's other beliefs that have a high degree of epistemic justification. This background web of beliefs with which we test new beliefs and judgments may be ethical but may also be metaphysical, meta-ethical, axiological, epistemic, and political in nature. Rather than walling off religious beliefs, the religious CEC and non-religious CEC alike need to utilize their background beliefs in the process of justifying their ethical judgments.

Whereas Malek worries about consistency, Parker sees disagreement as an irremediable feature of the moral world, in part, due to the plurality of background metaphysical, meta-ethical, axiological, epistemic, and political commitments that people bring to their moral judgments. Parker argues that authenticity rather than conformity should be the goal of CECs. He writes,

The essence of giving an independent moral judgment is one person telling another person what he truly believes about the moral features of a case... It is a commitment to the enterprise of morality as an end, not merely as a means. When we make and express moral judgments authentically, we express our commitment to being moral agents and moral reasoners. It does not mean that we always get it right, but it means we try really hard to get it right and that we honestly tell people what we think (Parker 2019, p. 114).

He goes on to argue that CECs' consultative practices should be characterized by the practice of reason giving, which is itself a way to show respect.

To respect other persons is not to accept their position or to offer only reasons that one thinks they might accept, but to be authentic, to be serious, to be truthful, to let them make up their own minds, and to try assiduously to avoid using coercive force to get them to act against their moral judgments once they have been made" (Parker 2019, p. 115).

In his article, "When Religion and Medicine Clash: Non-Beneficial Treatments and Hope for a Miracle", Philip Rosoff argues that neither religious nor non-religious reasons are sufficient to justify providing non-beneficial care to patients at the end of their life. He gives a case example in which a patient in a permanent vegetative state was kept a "full code" as the family prayed for "a miracle that would restore their wife and mother to her previous state of health" (Rosoff 2019, p. 122). Rosoff notes that sometimes this specific religious reason-waiting for a miracleis used to justify providing what he concludes is morally unjustified treatment. He argues, "While physicians also have a duty to be respectful of their patients' and their families' beliefs, they should not be compelled to deliver bad, non-beneficial or even harmful treatments solely in service of those beliefs" (Rosoff 2019, p. 130). Further,

...treatment that is not, or cannot, help patients achieve some reasonable chance of even a minimal amount of recovery... should not be employed under any circumstances. The reasons that patients may put forth, whether 
theological or secular, are irrelevant to the judgment that a given intervention-or suite of interventions_-is with benefit to the patient" (Rosoff 2019, p. 135).

So, Rosoff argues that with regards to continuing non-beneficial treatment at the end of life, religious and secular rationales are on equal epistemic footing in so far as both types of reasons fail to justify such treatment.

In his article, "Moral Conflicts and Religious Convictions: What Role for Clinical Ethics Consultants?", John Moskop gives us an interesting clinical case to ponder and then provides a taxonomy of approaches that the CEC might adopt when providing a consultation. He describes an authoritarian approach which "assigns primary decision-making authority to the clinical ethics consultant, because he or she is viewed as a moral expert "(Moskop 2019, p. 133); a pure consensus approach which" assigns to clinical ethics consultants the sole task of helping the primary stakeholders in a patient's care reach agreement on a course of action" (p. 144); and an ethics facilitation approach, based on the ASBH core competencies report, which "directs clinical ethics consultants to help stakeholders reach agreement on a course of action that is "within the bounds of ethical and legal standards""(Moskop 2019 , p. 144). He goes on to argue that each of these approaches has significant shortcomings.

Moskop then moves on to explore the CEC as advocate and the various advocacy roles that the CEC might adopt during a consultation including advocacy for the patient, clinician, or institution. As with the other approaches, these also have problems. Ultimately, Moskop concedes that universally satisfactory resolution may not be possible in deep moral conflict: "Conflicts between fundamentally different religious and secular moral commitments like this one may... illustrate inescapable limitations in current approaches to clinical ethics consultation" (Moskop 2019, p. 150).

Finally, in an insightful paper entitled "When Religious Language Blocks Discussion about Health Care Decision Making”, George Khushf explores the phenomenology of religious language in end of life decision-making and how such language can easily be misinterpreted. As with our other authors, Khushf uses a clinical case to illustrate this dynamic. He notes that sometimes in cases of perceived futility a surrogate's religiously based reluctance to limit care can be translated as a commitment to an uncritical vitalism; however, this is likely a mis-translation of the religiously based refusal. Rather, the real reasons behind the refusal may be based on a disagreement regarding the moral significance of withdrawing care. Khushf suggests that some religious believers may see no moral distinction between withdrawing care and active killing and rather than draw the conclusion that these are equally permissible, they draw the conclusion that these are equally wrong. Also, the religious believer may see continuing treatment in seemingly futile situations, not as an ultimate commitment to ongoing biological existence, but rather as testimony of their commitment to their loved one and to their trust in God regardless of how hopeless the situation may seem. Even if God chooses not to heal, the believer 
finds value in this testimony since it expresses his core, life-orienting convictions of God's power and goodness. ${ }^{1}$

Khushf notes that these types of translations are difficult and sometimes plagued by irremediable ambiguity; however, he concludes that the efforts at translation are worthwhile ${ }^{2}$ :

Until God decides, wheat and tares must remain entangled and the only proper response gives the benefit of doubt to the ones using the religious language. Sometimes our efforts will bear fruit. Other cases will go nowhere. In the end, God will do the sifting. Until that day, approach each case in the same way: with an openness, trust, and hope that the effort at understanding will be worth the effort (Khushf 2019, p. 166).

\section{Conclusion}

Religions often operate as comprehensive worldviews, attempting to answer the deepest existential questions that human beings can ask: Who am I? Where do I come from? Where am I going after I die? How should I live? Often ethical systems are embedded and justified within these broader narratives. Inevitably, the clinical ethics consultant will encounter and engage with religiously based ethical systems. In this issue, the authors reflect seriously and deeply on the implications of such engagement in a world in which there is no uniformly accepted religious system and moral disagreement looms prominently and persistently.

\section{References}

Khushf, G. (2019). When religious language blocks discussion about health care decision making. HEC Forum, 31(2), 151-166. https://doi.org/10.1007/s10730-019-09371-x.

Malek, J. (2019). The appropriate role of a clinical ethics consultant's religious worldview in consultative work: Nearly none. HEC Forum, 31(2), 91-102. https://doi.org/10.1007/s10730-018-9363-6.

Moskop, J. (2019). Moral conflicts and religious convictions: What role for clinical ethics consultants. HEC Forum, 31(2), 141-150. https://doi.org/10.1007/s10730-018-9350-y.

Parker, J.C. (2019). Religion, authenticity, and clinical ethics consultation. HEC Forum, 31(2), $103-117$.

Rosoff, P. (2019). When religion and medicine clash: Non-beneficial treatments and hope for a miracle. HEC Forum, 31(2), 119-139. https://doi.org/10.1007/s10730-018-9352-9.

Publisher's Note Springer Nature remains neutral with regard to jurisdictional claims in published maps and institutional affiliations.

\footnotetext{
1 For a biblical expression of this type of commitment, see Daniel 3:8-30.

2 See Matthew 13:24-30.
} 